\title{
Microalgae research worldwide
}

Jose Antonio Garrido-Cardenas ${ }^{1}$, Francisco Manzano-Agugliaro ${ }^{2}$, Francisco Gabriel Acien-Fernandez ${ }^{2}$ and Emilio Molina-Grima ${ }^{2 *}$

${ }^{1}$ Department of Biology and Geology, University of Almeria, 04120 Almeria, Spain; jcardena@ual.es.

${ }^{2}$ Department of Engineering, University of Almeria, 04120 Almeria, Spain; fmanzano@ual.es; facien@ual.es; emolina@ual.es.

*Corresponding author: F. Gabriel Acién Fernández, Department of Engineering, University of Almeria, 04120 Almeria, Spain, facien@ual.es

\section{Keywords}

Bibliometric, microalgae, publications, researchers, journals 


\begin{abstract}
In this paper, worldwide research trends in the microalgae field are analyzed based on a bibliometric study. We have looked at the number of publications and their distribution, as well as the most relevant journals and keywords, to determine the evolution and latest tendencies in this field. The results confirm that this is a fast-growing area in terms of the number of publications. The most relevant journals on this subject are Bioresource Technology and Algal Research. Although the majority of papers come out of the USA, the most relevant institutions are actually located in China, France and Spain. The most frequently cited strains are Chlorella and Chlamydomonas. The main keywords that appear in over 1,000 articles are generally related to microalgae cultivation applications such as 'biomass, biofuel, and lipids' while others are related to the methodology; for instance, 'bioreactor'. Of all the keywords, 'biomass' stands out, as it appears in almost $20 \%$ of publications. Bibliographic analysis confirms that Microalgae Biotechnology is a very active field, where scientific productivity has exponentially increased over recent years in tandem with industrial production. Therefore, expectations are high in this field for the near future.
\end{abstract}




\section{Introduction}

Microalgae biotechnology is a relatively new research area that has increased exponentially over the last few years in parallel with the rapid appearance of facilities and microalgae-based products. This field generally includes both eukaryotic microalgae and prokaryotic cyanobacteria - although they are biologically quite different microorganisms, the fundamentals of their production are similar as are the type of products/applications for which they are used. Today, these microorganisms are used to produce: (i) high-value compounds such as carotenoids, polyunsaturated fatty acids and phycobiliproteins, (ii) whole biomass that form part of nutraceuticals, foods and feeds, (iii) extracts or processed biomass to produce biofertilizers, which are also being proposed for biofuel production, or (iv) the living microorganisms used in bioremediation processes for wastewater, soils and flue gases (Spolaore et al. 2006). Whatever final application is being considered, the whole production process must be specifically designed to fit with it. Defining a general technology or process that can be used with any application is not possible.

Although microalgae have been described in biological processes [st1]over many the first studies on microalgae production under controlled conditions started in the 1950's (Burlew 1953). Over the following years, different types of photobioreactors were proposed such as raceways (Golueke and Oswald 1963) and tubular (Pirt et al. 1983); these reactors are still the most widely used. The first strains to be studied included Chlamydomonas, Chlorella and Spirulina, the latter two being the most cultivated worldwide today. Chlamydomonas has been extremely well studied from a physiological and genetic standpoint; it is a model microorganism in the study of microalgae photosynthesis and molecular biology. The first products obtained from microalgae were limited to the whole biomass, which were included in human foodstuffs or as feed for aquaculture. Since this time, the evolution of microalgae biotechnology has been based on four pillars: (i) looking for new strains capable of easy and rapid growth, which contain novel valuable compounds, (ii) knowledge of the strain's biology and the mechanisms regulating cell performance, (iii) improving production systems both in terms of efficiency and capacity, and (iv) developing new markets and products (Richmond 2000).

Concerning strains, although thousands of strains are available at numerous culture collections worldwide, only a few have been studied in detail. Strains like Dunaliella salina as a source of beta-carotene or Haematococcus pluvialis as a source of astaxanthin are good examples of new strains that have finally achieved commercialscale success (Leu and Boussiba 2014). However, hundreds of additional strains have been reported in the literature as sources of carotenoids. The reason why these strains have not achieved commercial-scale production is usually related to a lack of strain robustness or low productivity under outdoor conditions. Therefore, only strains capable of performing adequately under a wide range of culture conditions, including tolerance to adverse short-term conditions, can be produced outdoors. New strains that are now 
produced at the large-scale include Euglena and Porphyridium even though these strains' production capacity is much lower; this is because they are mainly used as food supplements or in cosmetics (Borowitzka 2013b). In addition, new seawater strains have been incorporated into the portfolio of commercially produced strains due to the aquaculture sector's requirement for high quality aquafeed for fish larvae and crustaceans - these include Nannochloropsis, Tetraselmis, Isochrysis and Chaetocceros amongst others (Muller-Feuga 2000).

Concerning strain biology and genetics, great effort has been made in recent years to elucidate the mechanisms involved in synthesizing target compounds as a prior step to increasing their accumulation in the biomass. Examples of this are the production of fatty acids and astaxanthin, to name but two (Han et al. 2013). In this area of research, methodologies developed for other organisms have usually been translated to microalgae but unfortunately this strategy has not been successful given the particularities of microalgae cells (their cell wall, etc.). Initially, selection strategies were used to obtain super-producing strains but the improvements achieved by this strategy were limited. Subsequently, mutation-selection strategies were tried but random mutagenesis usually reverts to the wild type after a few generations making this strategy similarly inefficient. In the last few years, advances in molecular biology have allowed specific mutation techniques to be applied that obtain stable overproducing strains (Guo et al. 2010; Dautor et al. 2014). Further developments in this field could greatly improve the performance of current or new strains.

With regard to production technology, different reactor types have been proposed such as $\alpha$-reactors, vortex reactors, flat-panel reactors, thin-layer reactors, vertical biofilm reactors and algae-disc reactors etc.; however, still the most extensively used reactors are raceway and tubular types (Posten 2009; Acién Fernández et al. 2013). The main issue for photobioreactors is maximizing strain performance to provide optimal conditions for the strains at minimal cost. Optimal conditions are usually dependant on the culture medium, the temperature and $\mathrm{pH}$, but especially on light availability to the cells. Calculating light availability in any photobioreactor has been a challenge although this has been solved by introducing the concept of average irradiance (Molina Grima et al. 1996). Providing optimal conditions at the small scale is possible using a multitude of different reactor designs but when increasing the reactor size, it is usually not possible to maintain such conditions. The main drawbacks in large reactors are related to the inability to control temperature, inadequate mixing, excessive power consumption and poor mass-transfer capacity (Fernández et al. 2012; Acien et al. 2013; Mendoza et al. 2013; de Godos et al. 2014). In addition to photobioreactor design, the harvesting strategy is also a major factor determining the suitability of large-scale microalgae production; this step accounts for up to $30 \%$ of the overall production cost (Grima et al. 2013). The challenge is always to achieve the highest production capacity at minimum cost; however, to achieve this objective, different technologies and strategies need to be used according to the particular location (Norsker et al. 2011; Acién et al. 2012). 
At the beginning of the 21th century, the proposition that microalgae could be a possible source of biofuels, along with the high oil price at that time, motivated large energy companies to take an interest in microalgae biotechnology, investing significant amounts of money to pursue that objective. Highly relevant papers were published that established the potential for these technologies (Chisti 2007; Wijffels and Barbosa 2010). However, the yield from real production systems was far from the theoretical values owing to bottlenecks that still limit biodiesel production from microalgae (Rodolfi et al. 2009). Unfortunately, adequate bioenergy production from microalgae remains unrealized. Nevertheless, the sizeable investment made over those years generated a leap in technology and production capacity that is now facilitating an expansion in commercial microalgae applications. Hence, in recent years, the technology has been improved to such an extent that, today, there are industrial facilities for both tubular and raceway reactors covering hundreds of hectares. Nevertheless, most of the microalgae biomass produced worldwide is still produced in open raceways (Benemann 2013). The production cost of microalgae biomass has dropped to $5 € / \mathrm{kg}$ and can be reduced yet further to below $1 € / \mathrm{kg}$ when coupled with wastewater treatment using $\mathrm{CO}_{2}$ capture from flue gases (Acién et al. 2012). Consequently, new microalgae applications focused on wastewater treatment are now being scaled up for industrial processes, the resultant cheap biomass produced being suitable for use in low-value markets such as biofertilizers. As a result, microalgae biotechnology will certainly continue to increase over the next few years, with both the technologies and products being improved and extended to new applications.

The major bottlenecks limiting the expansion of microalgae biotechnology are the high production costs and the small-scale of current production systems. Consequently, less than 20,000 t of biomass are produced worldwide, at a cost above $5 € / \mathrm{kg}$ (Borowitzka 2013a). This high production cost limits microalgae biomass applications mainly to high-value markets such as human foods and some aquaculture specialties (Vigani et al. 2015). The low production capacity means that the food industry does not consider this biomass as being realistically available for inclusion in large-scale food production processes, compared to other conventional materials such as cereals or vegetables, which are available in much greater quantities. To solve these problems, the production capacity must firstly be increased several orders of magnitude by developing more robust and efficient production systems. Secondly, the production cost must be reduced by increasing the production capacity. However, the larger reduction will be achieved by coupling biomass production with nutrient recovery from residuals. Of course, these advances must be further supported by continuous improvements in the performance of the microalgae strains produced, not only in terms of productivity and efficiency but also in biochemical composition and hence the value of the biomass produced.

The objective of this manuscript is to analyze the worldwide trends in microalgae research using the research output from Scopus to highlight any new perspectives on the topic. For this purpose, a bibliometric study can be used. Bibliometrics consist of using tools and methodologies to analyze and evaluate the results of all the literature 
generated on a research subject (Cobo et al. 2015). Using these tools, a variety of conclusions can be drawn such as: identifying the main institutions and the most important researchers in a research field, evaluating the most important milestones over the history of a scientific field, or predicting trends or scientific fads through the study of the evolution of the produced literature (Martínez et al. 2015). Over recent years, many bibliometric analyses have been carried out in different scientific areas that have shown the great usefulness of this methodology (Ellegaard and Wallin 2015; Juliani and de Oliveira 2016; Garrido-Cardenas and Manzano-Agugliaro 2017).

\section{Methodology}

In the present study, a complete search of the Elsevier Scopus database was carried out using [TITLE-ABS-KEY (microalga*)] as the search query. The search resulted in 22,278 documents being obtained after limiting the search timescale from 1970 to 2017. It should be noted that if different search parameters were used, the results would vary. The obtained results were processed by grouping keywords with identical meanings and discarding those that did not contribute to this study; for example, 'article'. Also, the most important data were selected, which were represented in a way to make them easier to understand. [st2] The aspects studied were: the number of publications per year, distribution of publications by institutions and by country, the major authors and the keywords. Communities detection was carried out using the VOSviewer software tool. This software allows one to elaborate graphs in which each country or keyword is represented by a node, and the connections between two nodes represent the collaboration between the two terms that the nodes represent.

The records obtained were conveniently processed using spreadsheets and a specific open-source coding tool, OpenRefine (http://openrefine.org/). This application "is a standalone desktop application initially developed by Google for data clean-up and transformation to other formats". The methodology allows for the straightforward analysis of unsorted, conflictive or disorganized text. Consequently, highly satisfactory results were obtained that would otherwise be nearly impossible to achieve given the extensive size of the database. This methodology has been used successfully in other bibliometric studies (Montoya et al. 2014; Montoya et al. 2016).

\section{Results}

\subsection{Evolution of the scientific output}

Figure 1 shows the evolution of the number of publications from 1970 to 2017. Before 1970, the number of publications on microalgae was not representative[st3], while 2017 the last year for which complete data are available. The results show that there were two clear trends over this period. The first was from 1970 to 2005 whereas the second began in 2005 and continued until the end of the study period. Both trends can be adjusted to straight paths with similar $\mathrm{R}^{2}$ coefficients but very different slope values. The first has a 
slope value of 11.6, while the second slope is more than fifteen-times greater, at 191.2. These slopes represent the increase in the number of publications per year, showing that, although interest in microalgae research increased throughout the studied period, it rose dramatically from 2005 onwards. The results also show that, in the last ten years, research in this field has continued to grow, reaching more than 2,700 publications a year by 2017; this being a great indicator of microalgae's importance in current research.

Most publications on microalgae $(81.45 \%)$ are articles. In second and third position, sharing similar values are conference papers and reviews; these are understood to be manuscripts that highlight the state of the art in a field without using original material. These two document types represent $6.46 \%$ and $5.88 \%$ of microalgae publications, respectively (Figure 2). Other documents appear at a lower frequency, such as book chapters, notes or short surveys. Because most of the studies were articles published in international journals, which are predominantly English-speaking, the most commonly used language was English, found in $95.45 \%$ of documents. Figure 3 shows the breakdown of the ten main languages used (one should note that a single document might be written in more than one language).

\subsection{Publication distribution by countries and institutions}

Figure 4 shows the top twelve institutions, accounting for more than 150 publications. From these top institutions, six are European (two Spanish, two French, one Russian and one Dutch) and six are non-European, principally Asian (three Chinese, one Korean, one Taiwanese and one Israeli)[st4]. However, if the analysis is performed by country rather than by institution (Figure 5), the results show that first place is occupied by the USA, followed by China, Spain and then France. Looked at from this perspective, the USA leads the ranking in the number of publications on microalgae with more than 3,500 articles over the studied period; yet they still do not have any institution in predominant positions. This is explained because there are up to 70 American institutions with at least 20 publications on microalgae each, while there are only 55 Chinese, 35 French and 29 Spanish institutions with an equivalent number. In these latter countries, the weight of research into this subject rests mainly on single institutions - the Chinese Academy of Sciences in China, the CNR (Centre National de la Recherche Scientifique) in France, and the University of Almeria in Spain - whereas in the USA, interest in this area is far more homogeneously distributed between research centers, or is less specialized in this field. Other countries such as Australia and India are well positioned in the ranking for the number of publications but their institutions are not amongst those that produce more scientific literature since their situation is like that previously explained for the USA.

Figure 6 shows a world map in which the scientific production of each country is color highlighted. The red color indicates a greater number of publications, the blue color indicates a lower number, and white indicates that none exist. One can observe that, geographically, this field of study is mainly relevant in the USA, China, Japan, Europe 
and Australia. Obtaining the inhabitants data from http://www.worldometers.info/world-population/population-by-country/, the value of the scientific production by country was normalized (Table 1). The results show that the top position goes to Australia with more than 48 publications per million inhabitants, followed by Spain with more than 34. Countries such as China or India, with populations over one billion people, occupy the last positions in this normalized ranking.

Figure 7 shows a distribution by communities of the countries that have published at least 300 articles on microalgae. The 21 countries that appear in this figure are distributed over 4 large communities. The first community is formed by Asian countries, along with Australia and the USA. The second is formed by European countries, along with Mexico and Brazil. The third community is formed by Germany and Russia while Canada constitutes a community unto itself. Globally, one can observe the central role played by the USA, and the large number of connections that exist between the countries with the greatest potential. Of these, it is remarkable how many connections exist between researchers from China and the USA in terms of collaborations on microalgae publications.

\subsection{Sources}

Communities of countries and their associations in publications on microalgae

Figure 8 shows the evolution of the seven journals that published at least 100 articles on microalgae from 2000 to 2017 . The results show that there are four journals that have kept their scientific production practically constant since 2000: Aquaculture, Journal of Phycology, Marine Ecology Progress Series, and Journal of Experimental Marine Biology and Ecology. On the other hand, three journals have shown a positive evolution in their scientific production, especially from the year 2009: Bioresource Technology, Algal Research and Journal of Applied Phycology. In absolute terms, Bioresource Technology is the fastest growing journal whilst in percentage terms, Algal Research is the journal with the greatest tendency for growth in this scientific field, reaching the second position overall in 2017, whereas the former has a declining trend in publications in this field.

In addition, Figure 9 shows the total number of published items that are related to the value of the Impact Factor from the JCR (calculated from the Web of Science database, formerly part of Thomson Reuters) and the CiteScore from the SJR (calculated by Elsevier from the Scopus database). [st5]One can see how both indexes follow the same trend, being good indicators of the citations received by the journals. The relationship between the number of published items and the impact indexes is observed mainly in the first two journals from the ranking: Bioresource Technology and Algal Research, whereas for the other journals, this is no longer reproduced[st6]. 


\subsection{Keyword analysis}

To carry out the analysis of the keywords, we first discarded all those that contributed nothing to the study and/or were obvious, such as 'microalgae' or 'article'. The results are shown in two different formats: a bar diagram and a cloudword (Figure 10). In both cases, only the keywords that appear in at least 1,000 articles are represented. These mainly include terms related to the microalgae cultivation applications, such as 'biomass', 'biofuel' or 'lipids'. Although others also appear that are related to the studied organism, such as 'Chlorella' or 'Green Alga', and some related to the methodology such as 'bioreactor'. Out of all of them, 'biomass' and 'biofuel' stand out, as they appear in almost $20 \%$ of publications.

Figure 11 shows the communities distribution of all the keywords appearing in at least 150 articles, and the connections established around them. As can be observed, 8 communities appear, each identified by a color. The two main communities are represented by the colors green and red. The green community revolves around the keywords 'wastewater' and 'Chlorella', probably influenced by the importance of research related to wastewater treatment using $C$. vulgaris. The red community is centered on the keywords 'photosynthesis', 'nutrients', and 'growth', influenced by the large number of publications focused on the optimization of microalgae culture conditions.

The seven microalgae genera appearing in the keywords of the studied articles are analyzed individually (2). Firstly, the distribution of articles by country has been represented. Next, the different genres were taken as the abscissas axis. Through the analysis of both representations, we verified that the interest for each microalgae is not the same for the countries studied. Hence, one can see that Chlamydomonas and Nannochloropsis are mostly studied in the USA; Chlorella and Scenedesmus are studied mainly in China; and Phaeodactylum and Isochrysis, in Spain. The seventh most present microalgae in the literature, Spirulina, is curiously not one of the most studied microalgae in any of the 10 countries with the highest number of publications in this area; it is instead most studied in Brazil.

A keywords analysis of the four countries with the highest scientific production (the USA, China, Spain and France) was also carried out and the results are represented in four cloudwords (Figure 12). It can be observed how, in the case of the USA, the obtained cloudword is practically identical to the general cloudword (Figure 10B). The only difference one could highlight is the increase in the size of the keywords 'photosynthesis' and 'nitrogen'. Nevertheless, there are differences in the other three cloudwords. In the case of China, the terms 'cyanobacterium' and 'phytoplankton' disappear, while 'phosphorus' and 'Scenedesmus' appear. Furthermore, the increase in size of 'nitrogen' and the reduction in size of 'diatoms' is remarkable. On the other hand, 'biodiesel' and 'cyanobacterium' disappear from the cloudword for Spain, with respect to the general graph, while 'Phaedactylum tricornutum' and 'wastewater' appear. In addition, the increase in size of 'bioreactor' is emphasized, as is the 
significant decrease of 'biofuel'. For the last cloudword, that of France, the term 'biodiesel' disappears, while 'bacillariophyta' appears. 'Photosynthesis', 'diatoms' and 'phytoplankton' increase in size while 'biofuel' and 'fatty acids' decrease.

Finally, we studied the time evolution of the publications for the seven most important microalgae (Figure 13). This analysis was performed for the last 20 years, 1997-2017, since these are the years for which we have complete data. Prior to 1997, the number of publications was negligible for each species. For Chlorella, the number of published articles is 73 while for the other genres, it is less than 25. In this study, similar behavior is seen for all microalgae: in the 1997 to 2010 period, growth was moderate. As of 2010, growth is remarkable, especially for Chlorella. The rest of the species are divided into two groups. On the one hand, for Chlamydomonas, Scenedesmus and Nannochloropsis, the takeoff was also considerable although well below Chlorella. On the other hand, for Phaeodactylum, Isochrysis and Spirulina, although the number of publications around them also increased, it happened in a very moderate way.

\section{Conclusions}

Analyzing the number of publications on microalgae from 1970 to 2017 , a great increase in the evolution is shown, which is especially outstanding from the year 2005 onwards. This is consistent with the increase over recent years in the market demand for microalgae-derived products and the great boom in the number of facilities for microalgae cultivation (Forján et al. 2014). In this study, in addition to the trend regarding the number of publications, other variables related to scientific production have been studied, such as the types and languages of publications, the major authors and the institutions. Thus, most of the publications are articles $(81.45 \%)$ and, to a lesser extent, conference paper (6.46) and reviews (5.88\%), and almost all are written in English (95.20\%). Most of these articles are published by two sources: Bioresource Technology and Algal Research. Both published $15.35 \%$ of all articles on microalgae in 2017.

The country publishing most on this subject is the United States (3,615 publications), followed by China (3,005 publications). Next, but far behind, are two European countries, Spain and France (1,593 and 1,456 articles, respectively). Looking at the institutions that publish the most, it can be seen that, amongst the former, there are none from the USA as would be expected. This is because the institutions that occupy the top positions in the ranking of publications occupy very prominent places within their respective countries in terms of microalgae research whereas, in the United States, there is an extensive network of institutions focused on microalgae study, none of which especially stand out above the others.

When the keywords for article in microalgae publications are studied, it can be seen that the one with the highest presence, 'biomass', is related to the first product of interest obtained from these organisms. The next term with the greatest presence is 'biofuel'. This is consistent with the significant interest aroused by microalgae as a bioenergetic 
resource; even though, to date, this line has not had all the success that was expected. Other keywords that appear in high ranking positions relate to microalgae applications in the market like 'lipids' or 'fatty acids'.

Observing the strains that are most present in the scientific literature, we can see how the first positions are occupied by those most classically studied, Chlorella and Chlamydomonas. Nonetheless, we have also been able to verify how interest in a certain strain largely depends on the country where it is studied. For example, in the USA there is more interest is in the two strains mentioned above whereas in China, Scenedesmus occupies a prominent position; in Spain, the most studied microalgae is Phaeodactylum and in Brazil, Spirulina. Other strains such as Dunaliella, Euglena, Porphyridium or Haematococcus are not yet widely present in the scientific literature, but it is expected that over the coming years, the number of publications that study them will increase considerably (Medipally et al. 2015; Yee 2016).

\section{Acknowledgements}

This research was funded by the SABANA project (grant \# 727874) from the European Union's Horizon 2020 Research and Innovation program.

\section{References}

Acién FG, Fernández JM, Magán JJ, Molina E (2012) Production cost of a real microalgae production plant and strategies to reduce it. Biotechnol Adv 30:13441353

Acien FG, Fernandez JM, Molina-Grima E (2013) Economics of Microalgae Biomass Production. Biofuels from Algae 313-325 . doi: 10.1016/B978-0-444-595584.00014-0

Acién Fernández FG, Fernández Sevilla JM, Molina Grima E (2013) Photobioreactors for the production of microalgae. Rev Environ Sci Bio/Technology 12:131-151

Alonso DL, Belarbi EH-H, Fernández-Sevilla JM, Rodríguez-Ruiz J, Grima EM, Fernández-Sevilla JM, Rodríguez-Ruiz J, Grima EM (2000) Acyl lipid composition variation related to culture age and nitrogen concentration in continuous culture of the microalga Phaeodactylum tricornutum. Phytochemistry 54:461-471 . doi: 10.1016/S0031-9422(00)00084-4

Benemann J (2013) Microalgae for biofuels and animal feeds. Energies 6:5869-5886

Blanken W, Cuaresma M, Wijffels RHRH, Janssen M (2013) Cultivation of microalgae on artificial light comes at a cost. Algal Res 2:333-340 . doi: 10.1016/j.algal.2013.09.004

Borowitzka MA (2013a) High-value products from microalgae-their development and commercialisation. J Appl Phycol 25:743-756

Borowitzka M a. (2013b) High-value products from microalgae-their development and commercialisation. J Appl Phycol 25:743-756 . doi: 10.1007/s10811-013-9983-9 
Burlew JS (1953) Algal culture from laboratory to pilot plant. Carnegie Institution, Washington, USA, pp 235-281

Chang JS, Yang JW, Lee DJ, Hallenbeck PC (2015) Editorial. Advances in biofuels and chemicals from algae. Bioresour Technol 184:1 . doi:

10.1016/j.biortech.2015.03.027

Chen CY, Zhao XQ, Yen HW, Ho SH, Cheng CL, Lee DJ, Bai FW, Chang JS (2013) Microalgae-based carbohydrates for biofuel production. Biochem Eng J 78:1-10 . doi: 10.1016/j.bej.2013.03.006

Chisti Y (2007) Biodiesel from microalgae. Biotechnol Adv 25:294-306

Cobo MJ, Martínez MA, Gutiérrez-Salcedo M, Fujita H, Herrera-Viedma E (2015) 25 years at Knowledge-Based Systems: A bibliometric analysis. Knowledge-Based Syst 80:3-13 . doi: 10.1016/j.knosys.2014.12.035

Dautor Y, Úbeda-Mínguez P, Chileh T, García-Maroto F, Alonso DL (2014) Development of genetic transformation methodologies for an industriallypromising microalga: Scenedesmus almeriensis. Biotechnol Lett 36:2551-2558 . doi: 10.1007/s10529-014-1641-z

de Godos I, Mendoza JL, Acién FG, Molina E, Banks CJ, Heaven S, Rogalla F (2014) Evaluation of carbon dioxide mass transfer in raceway reactors for microalgae culture using flue gases. Bioresour Technol 153:307-314 . doi: 10.1016/j.biortech.2013.11.087

Ellegaard O, Wallin JA (2015) The bibliometric analysis of scholarly production: How great is the impact? Scientometrics 105:1809-1831 . doi: 10.1007/s11192-015$1645-\mathrm{z}$

Fernández I, Acién FG, Fernández JM, Guzmán JL, Magán JJ, Berenguel M (2012) Dynamic model of microalgal production in tubular photobioreactors. Bioresour Technol 126:172-181 . doi: 10.1016/j.biortech.2012.08.087

Forján E, Navarro F, Cuaresma M, Vaquero I, Ruíz-Domínguez MC, Gojkovic Ž, Vázquez M, Márquez M, Mogedas B, Bermejo E, Girlich S, Domínguez MJ, Vílchez C, Vega JM, Garbayo I (2014) Microalgae: Fast-Growth Sustainable Green Factories. Crit Rev Environ Sci Technol 45:1705-1755 . doi: $10.1080 / 10643389.2014 .966426$

Garrido-Cardenas JA, Manzano-Agugliaro F (2017) The metagenomics worldwide research. Curr Genet. doi: 10.1007/s00294-017-0693-8

Golueke CG, Oswald WJ (1963) Power from solar energy_-Via algae-produced methane. Sol Energy 7:86-92 . doi: 10.1016/0038-092X(63)90033-1

Grima EMM, Fernández FGA, Medina AR, Acién Fernández FG, Robles Medina A (2013) Downstream Processing of Cell Mass and Products

Guo M, Bian X, Wu X, Wu M (2010) Agrobacterium-Mediated Genetic Transformation: History and Progress. Genet Transform 328 . doi: 10.5772/22026

Han D, Li Y, Hu Q (2013) Astaxanthin in microalgae: Pathways, functions and 
biotechnological implications. 28:131-147

Juliani F, de Oliveira OJ (2016) State of research on public service management: Identifying scientific gaps from a bibliometric study. Int J Inf Manage 36:10331041 . doi: 10.1016/j.ijinfomgt.2016.07.003

Leu S, Boussiba S (2014) Advances in the Production of High-Value Products by Microalgae. Ind Biotechnol 10:169-183 . doi: 10.1089/ind.2013.0039

Martínez MA, Cobo MJ, Herrera M, Herrera-viedma E (2015) Analyzing the scientific evolution of social work using science mapping. Res Soc Work Pract 25:257-277 . doi: $10.1177 / 1049731514522101$

Medipally SR, Yusoff FM, Banerjee S, Shariff M (2015) Microalgae as sustainable renewable energy feedstock for biofuel production. Biomed Res. Int. 2015

Mendoza JL, Granados MR, de Godos I, Acién FG, Molina E, Heaven S, Banks CJ (2013) Oxygen transfer and evolution in microalgal culture in open raceways. Bioresour Technol 137:188-195 . doi: 10.1016/j.biortech.2013.03.127

Molina Grima E, Acién Fernández FG, García Camacho F, Camacho Rubio F, Chisti Y (2000) Scale-up of tubular photobioreactors. J Appl Phycol 12:355-368

Molina Grima E, Fernández Sevilla JM, Sánchez Pérez JA, García Camacho F, MolinaGrima E, Sevilla JMF, Pérez JAS, Camacho FG (1996) A study on simultaneous photolimitation and photoinhibition in dense microalgal cultures taking into account incident and averaged irradiances. J Biotechnol 45:59-69 . doi: 10.1016/0168-1656(95)00144-1

Montoya FG, Baños R, Meroño JE, Manzano-Agugliaro F (2016) The research of water use in Spain. J Clean Prod 112:4719-4732 . doi: 10.1016/j.jclepro.2015.06.042

Montoya FG, Montoya MG, Gómez J, Manzano-Agugliaro F, Alameda-Hernández E (2014) The research on energy in Spain: A scientometric approach. Renew. Sustain. Energy Rev. 29:173-183

Muller-Feuga A (2000) The role of microalgae in aquaculture: situation and trends. J Appl Phycol 12:527-534 . doi: 10.1023/A:1008106304417

Norsker N-H, Barbosa MJ, Vermuë MH, Wijffels RH (2011) Microalgal production--a close look at the economics. Biotechnol Adv 29:24-7

Pirt SJ, Lee YK, Walach MR, Watts Pirt M, Balyuzi HHM, Bazin MJ (1983) A tubular bioreactor for photosynthetic production of biomass from carbon dioxide: Design and performance. J Chem Technol Biotechnol 33B:35-58 . doi: 10.1002/jctb.280330105

Posten C (2009) Design principles of photo-bioreactors for cultivation of microalgae. Eng Life Sci 9:165-177 . doi: 10.1002/elsc.200900003

Richmond A (2000) Microalgal biotechnology at the turn of the millennium: A personal view. J Appl Phycol 12:441-451

Rodolfi L, Zittelli GC, Bassi N, Padovani G, Biondi N, Bonini G, Tredici MR (2009) 
Microalgae for oil: Strain selection, induction of lipid synthesis and outdoor mass cultivation in a low-cost photobioreactor. Biotechnol Bioeng 102:100-112 . doi: 10.1002/bit.22033

Spolaore P, Joannis-Cassan C, Duran E, Isambert A (2006) Commercial applications of microalgae. J Biosci Bioeng 101:87-96

Vigani M, Parisi C, Rodríguez-Cerezo E, Barbosa MJ, Sijtsma L, Ploeg M, Enzing C (2015) Food and feed products from micro-algae: Market opportunities and challenges for the EU. Trends Food Sci Technol 42:81-92

Wijffels RHRH, Barbosa MJMJMJ (2010) An outlook on microalgal biofuels. Science (80- ) 329:796-9 . doi: 10.1126/science.1189003

Wijffels RHRH, Kruse O, Hellingwerf KJKJ (2013) Potential of industrial biotechnology with cyanobacteria and eukaryotic microalgae. Curr Opin Biotechnol 24:405-413 . doi: 10.1016/j.copbio.2013.04.004

Yee W (2016) Microalgae from the Selenastraceae as emerging candidates for biodiesel production: a mini review. World J. Microbiol. Biotechnol. 32:1-11 


\section{Captions}

Table 1.- Publication distribution by countries

Figure 1.- Trend in the number of publications from 1970 to 2017

Figure 2.- Distribution of document types for microalgae

Figure 3.- Principal languages used and number of publications

Figure 4.- Top 12 institutions by number of scientific publications on microalgae

Figure 5.- Top 10 countries in scientific output on microalgae

Figure 6.- World map with main countries and their number of scientific publications on microalgae

Figure 7.- Communities of countries and their associations in publications on microalgae

Figure 8.- Trend for the main sources in the number of publications from 2000 to 2017

Figure 9.- Total number of publications related to the value of the Impact Factor in JCR, and the CiteScore in SJR[st7]

Figure 10.- Different representations of keywords. A) Bar chart. B) Cloudword

Figure 11.- Communities of keywords and their associations in publications on microalgae

Figure 11.- .- Representation of the number of publications related to each genre and to each country. A) By country. B) By microalgae[st8]

Figure 12.- Cloudword of the four countries with the highest scientific production on microalgae

Figure 13.- Time evolution of the publication numbers of the most studied microalgae genres 
Table 2.- Publication distribution by countries.

\begin{tabular}{|l|r|r|r|}
\hline \multicolumn{1}{|c|}{ Country } & No. publications & $\begin{array}{c}\text { Population } \\
\text { (million inhabitants) }\end{array}$ & No. pub / mill. inhab. \\
\hline USA & 3615 & 326.747 & 11.06 \\
\hline China & 3005 & 1388.232 & 34.58 \\
\hline Spain & 1593 & 46.070 & 22.42 \\
\hline France & 1456 & 64.938 & 0.90 \\
\hline India & 1206 & 1342.512 & 48.33 \\
\hline Australia & 1191 & 24.641 & 8.89 \\
\hline Germany & 1145 & 80.636 & 16.65 \\
\hline Japan & 1120 & 126.045 & 20.69 \\
\hline UK & 1091 & 65.511 & \\
\hline South Korea & 1049 & 50.705 & \\
\hline
\end{tabular}




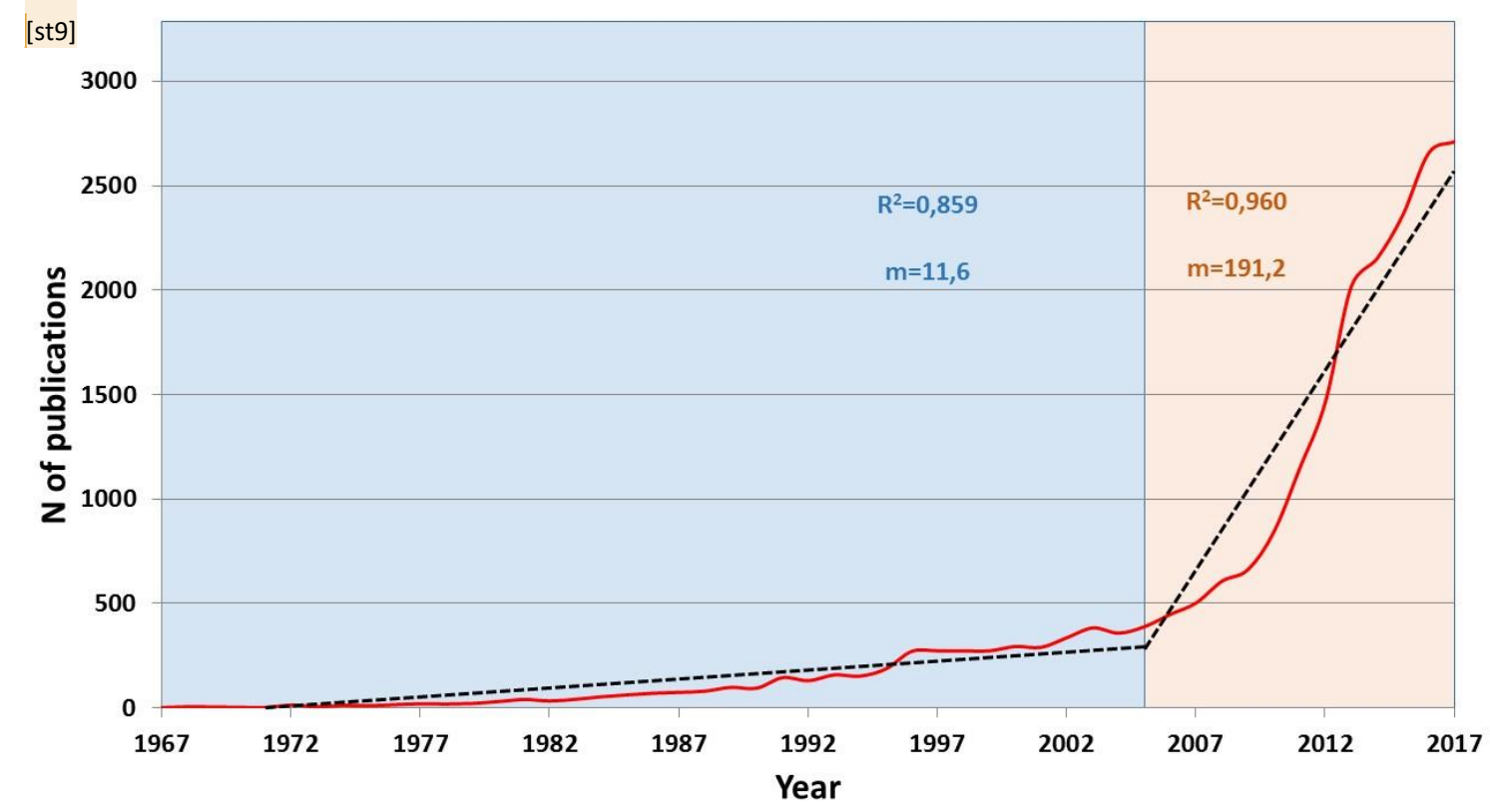

Figure 14.- Trend in the number of publications from 1970 to 2017 


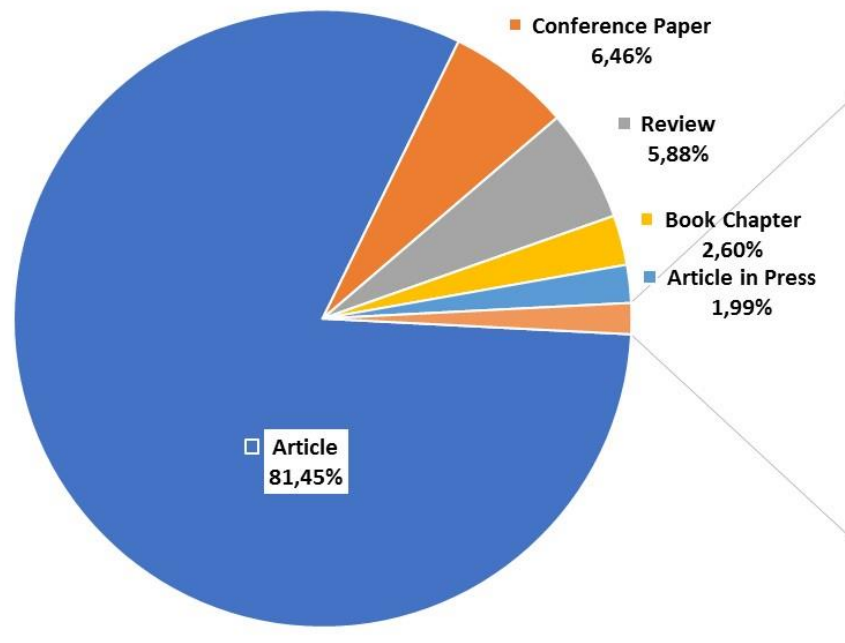

Others $<1 \%$

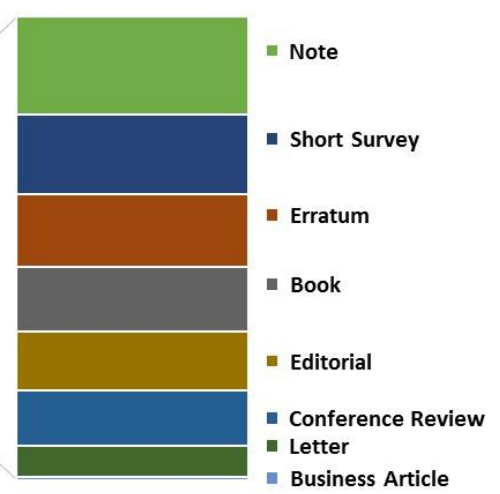

Figure 15.- Distribution of document types for microalgae 


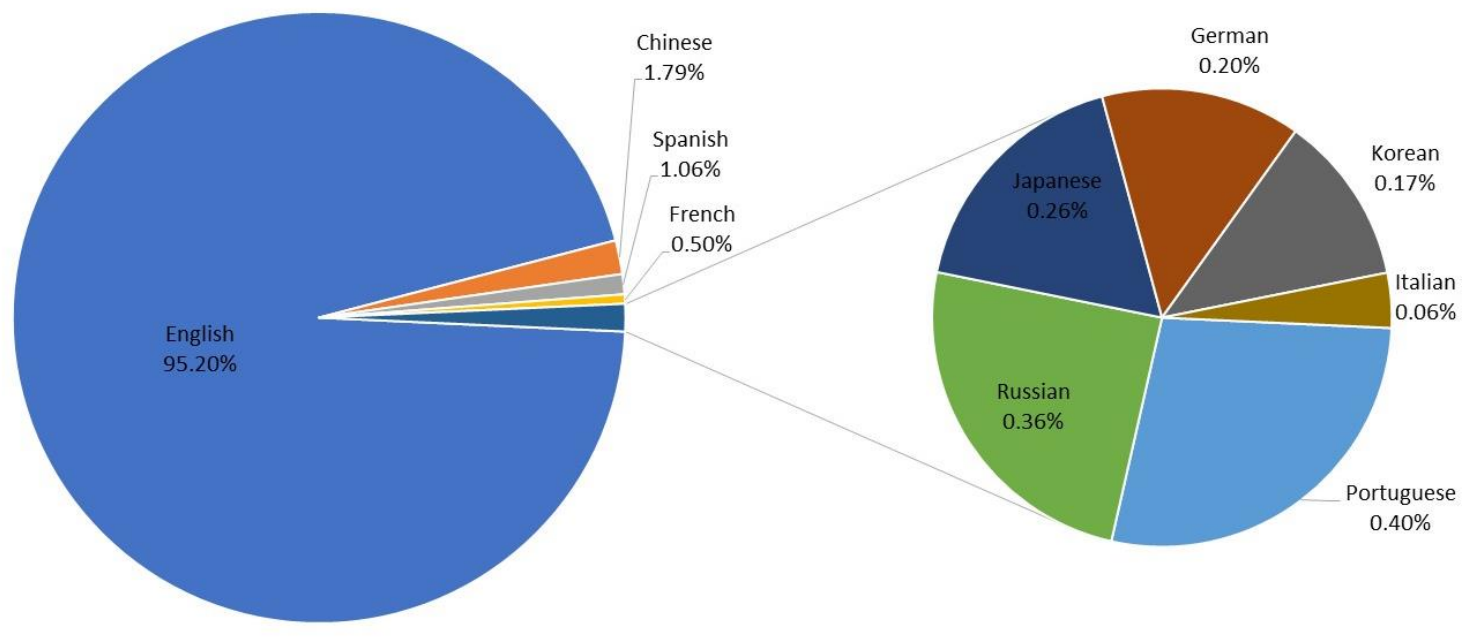

Figure 16.- Principal languages used and number of publications 


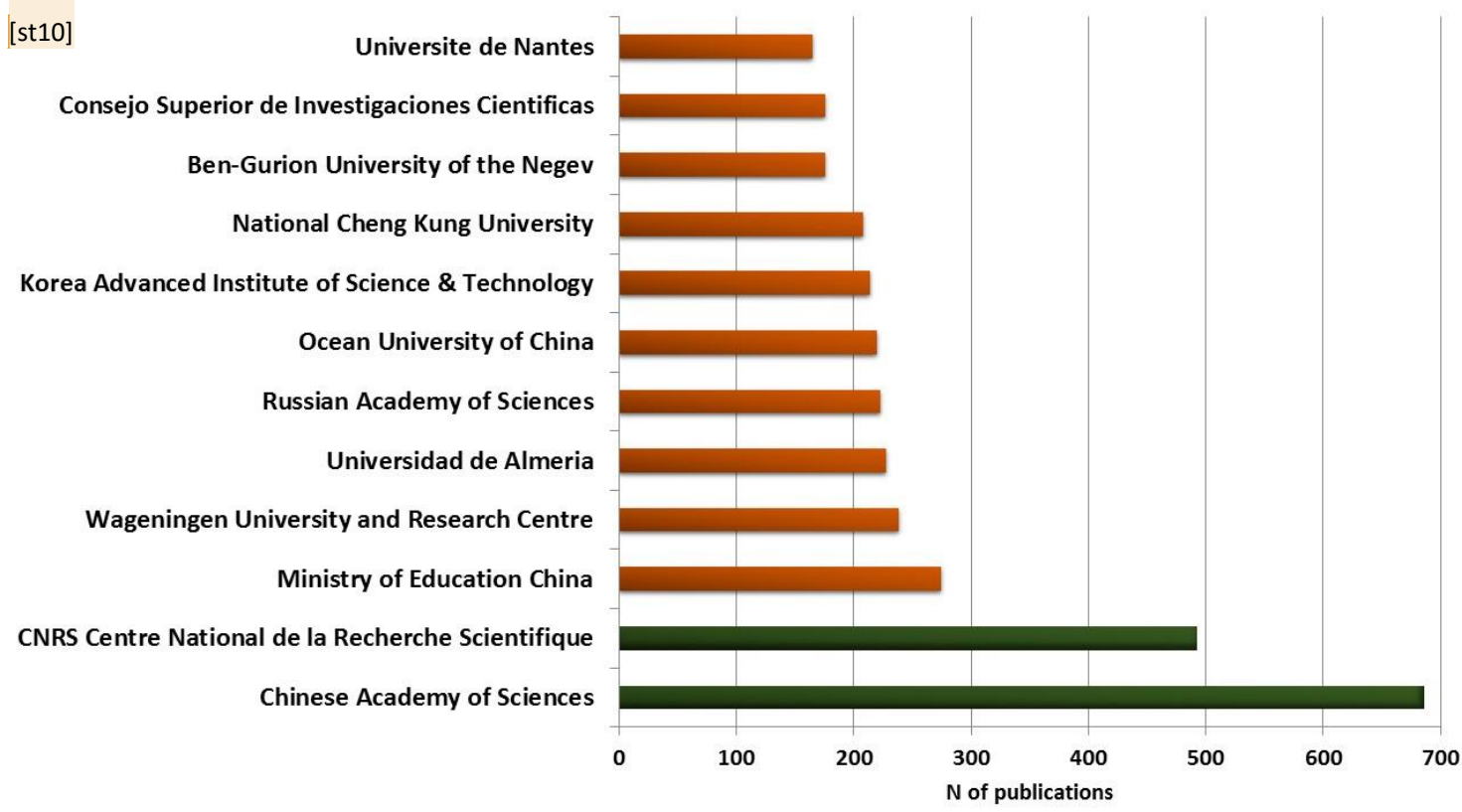

Figure 17.- Top 12 institutions by number of scientific publications on microalgae 


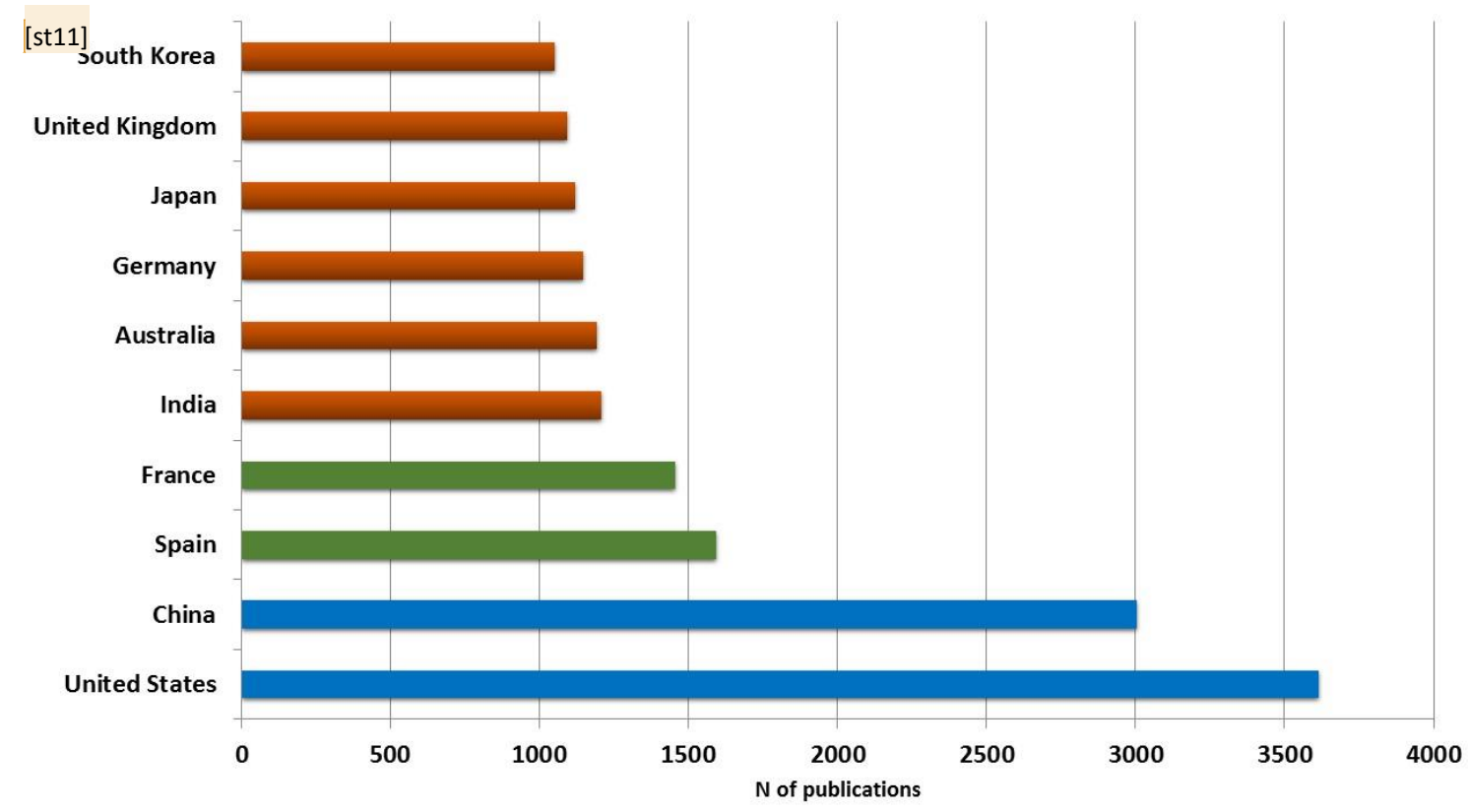

Figure 18.- Top 10 countries in scientific output on microalgae 
Figure 19.- World map with main countries and their number of scientific publications on microalgae 


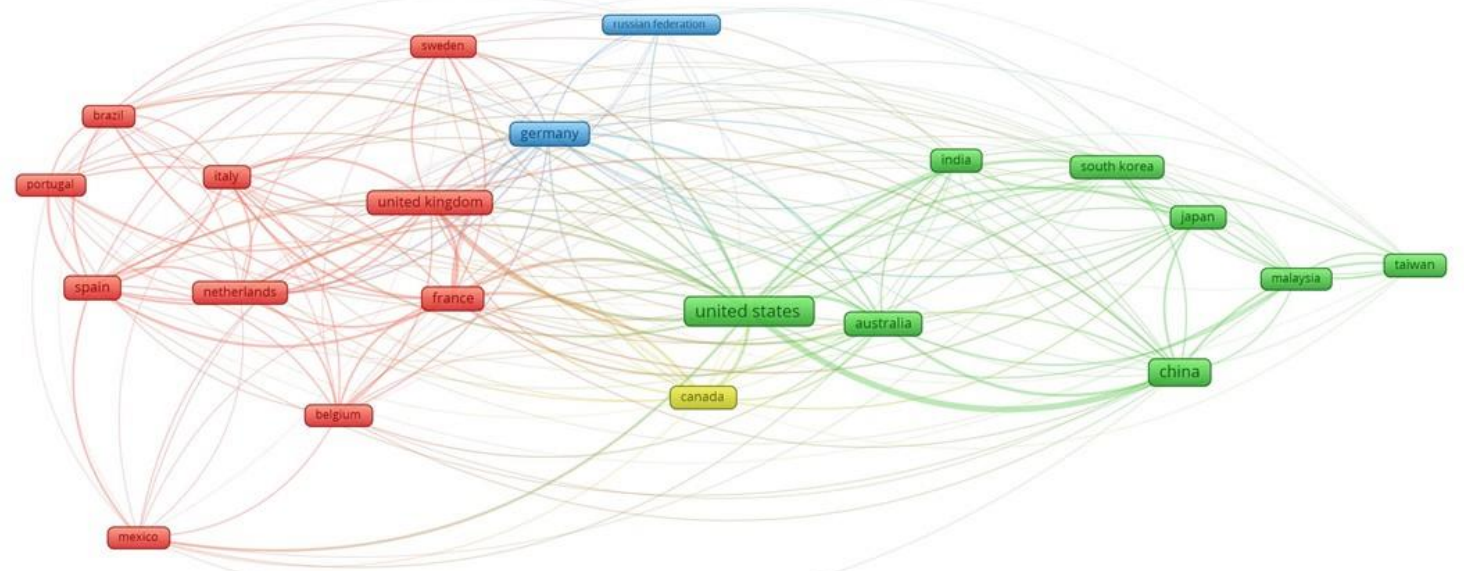

Figure 7.- Communities of countries and their associations in publications on microalgae 


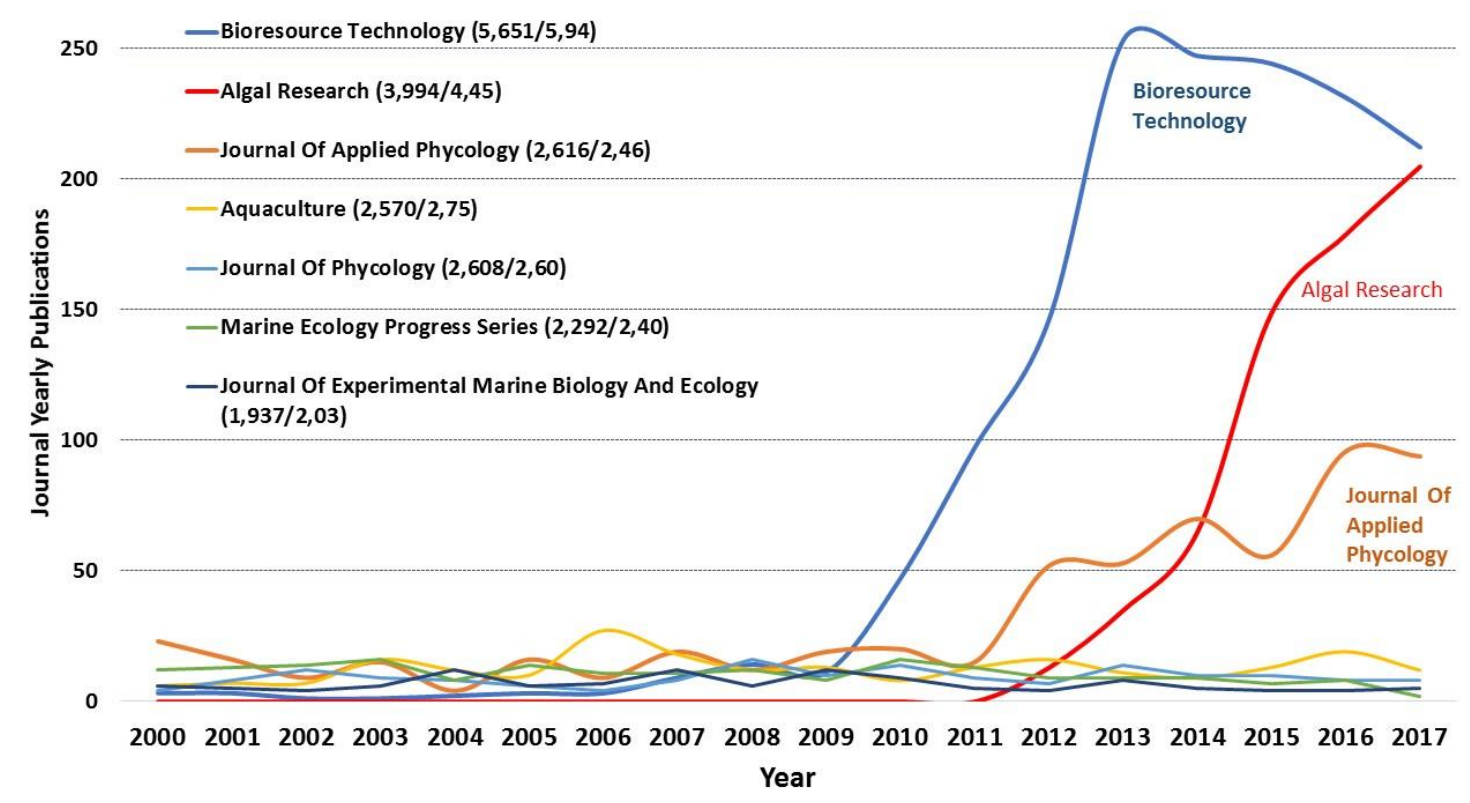

Figure 20.- Trend for the main sources in the number of publications from 2000 to 2017 


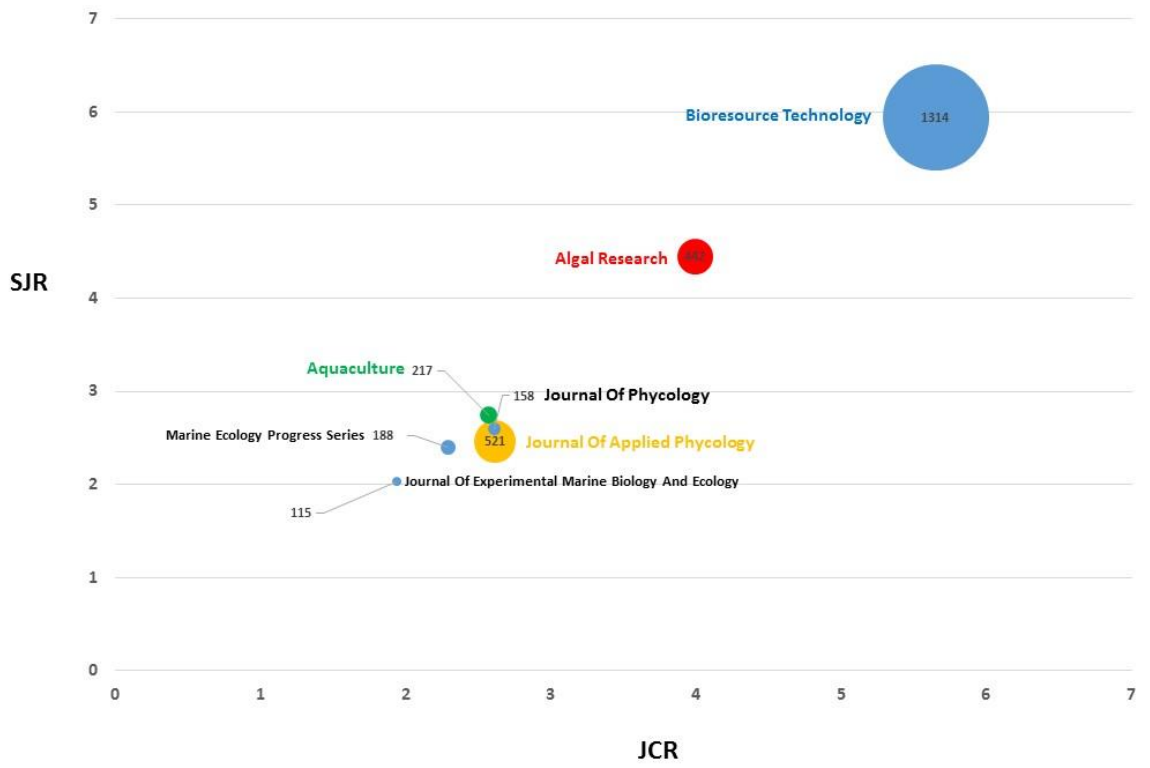

Figure 21.- Total number of publications related to the value of the Impact Factor in JCR, and the CiteScore in SJR[st12] 

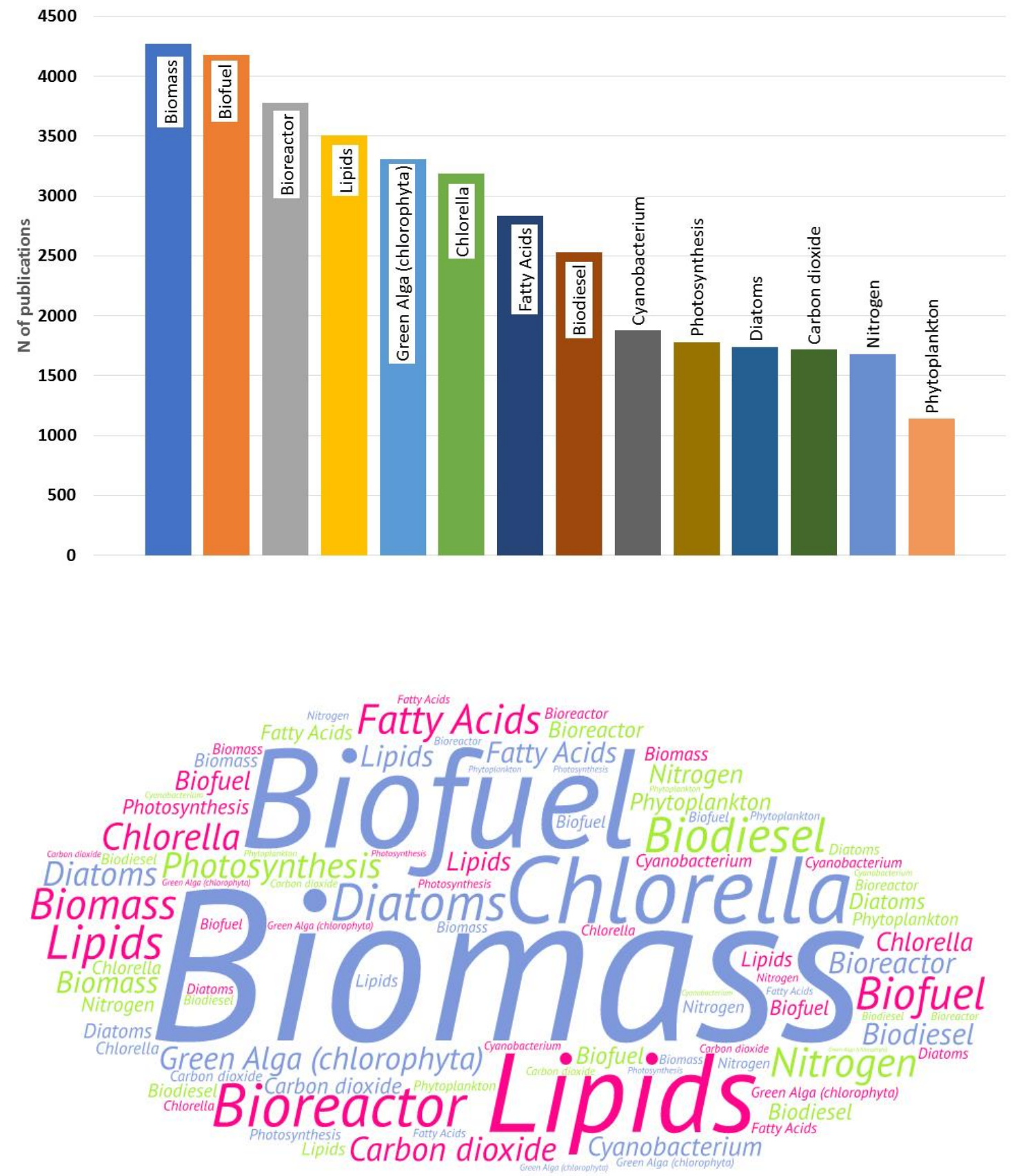

Figure 22.- Different representations of keywords. A) Bar chart. B) Cloudword 


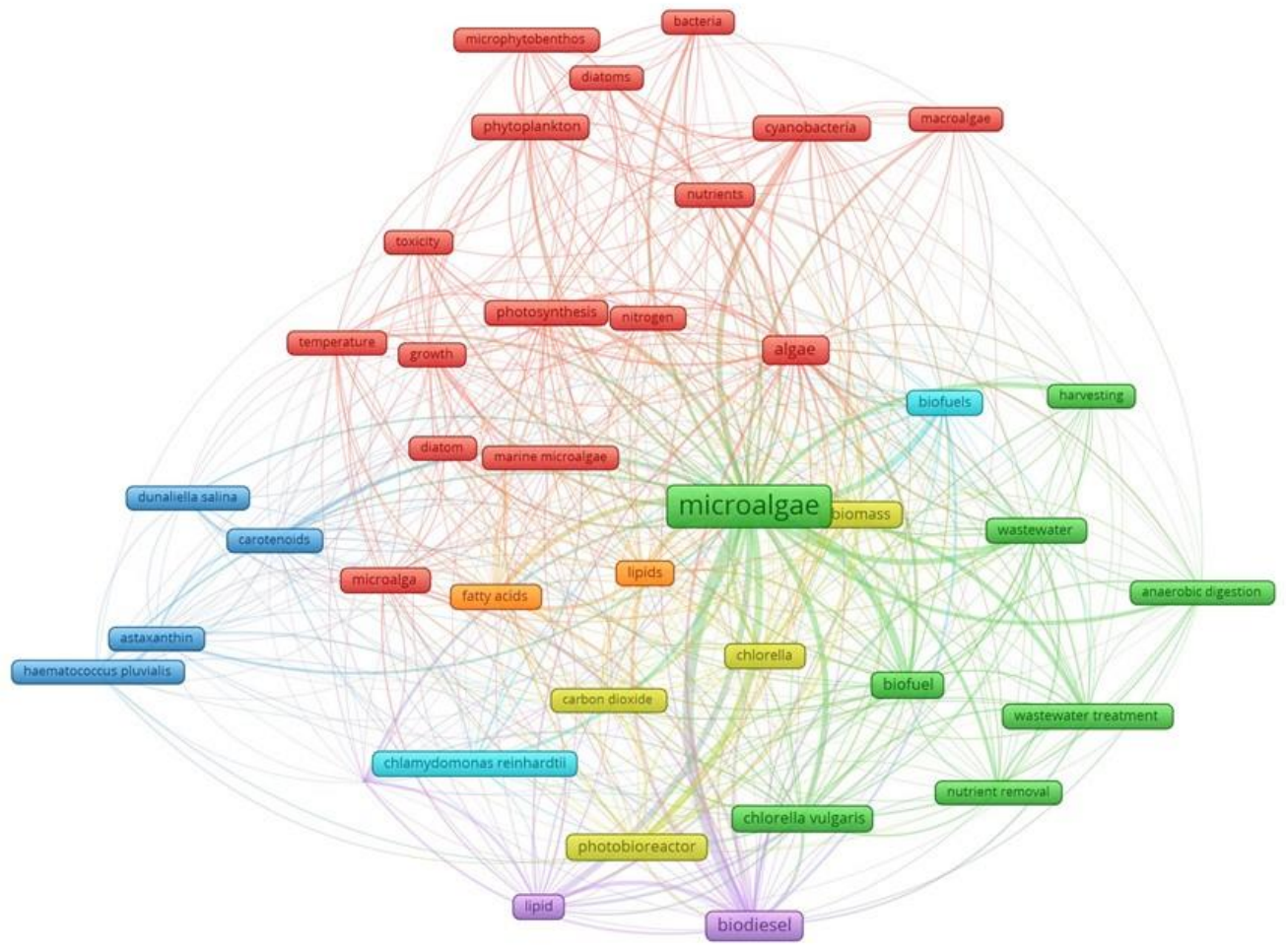

Figure 11.- Communities of keywords and their associations in publications on microalgae 

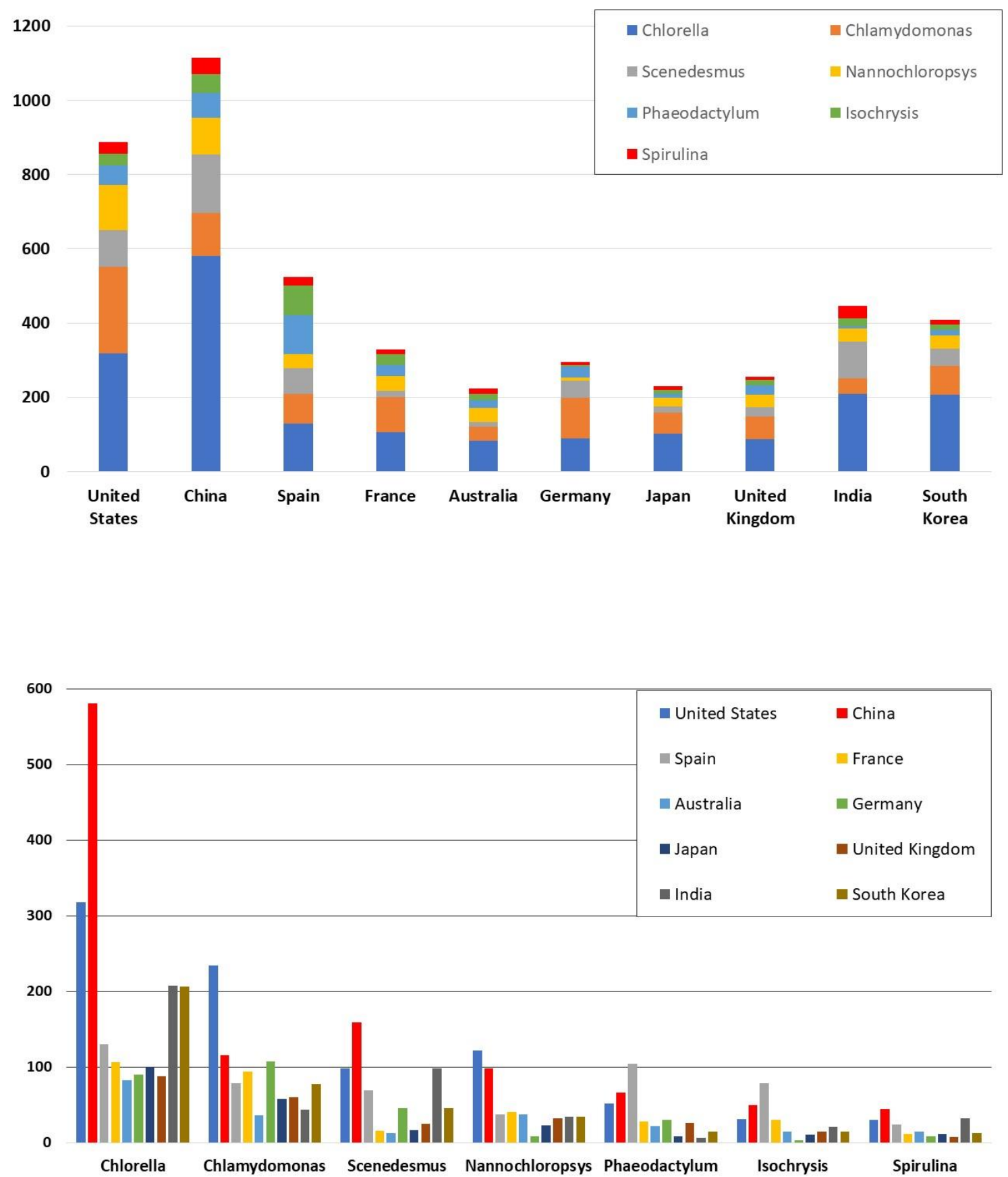
Figure 23.- Representation of the number of publications related to each genre and to each country. A) By country. B) By microalgae[st13]

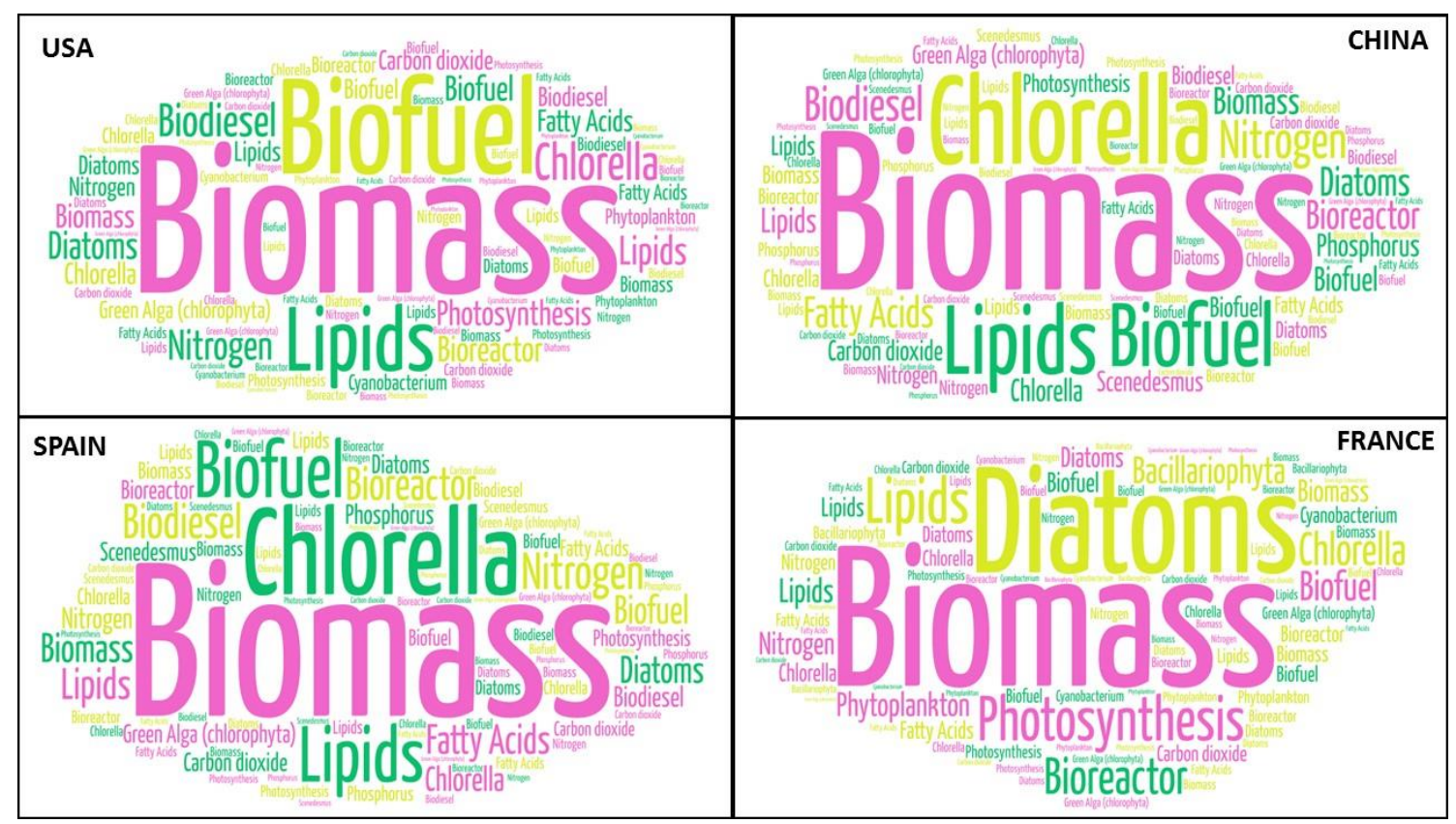

Figure 24.- Cloudword of the four countries with the highest scientific production on microalgae 


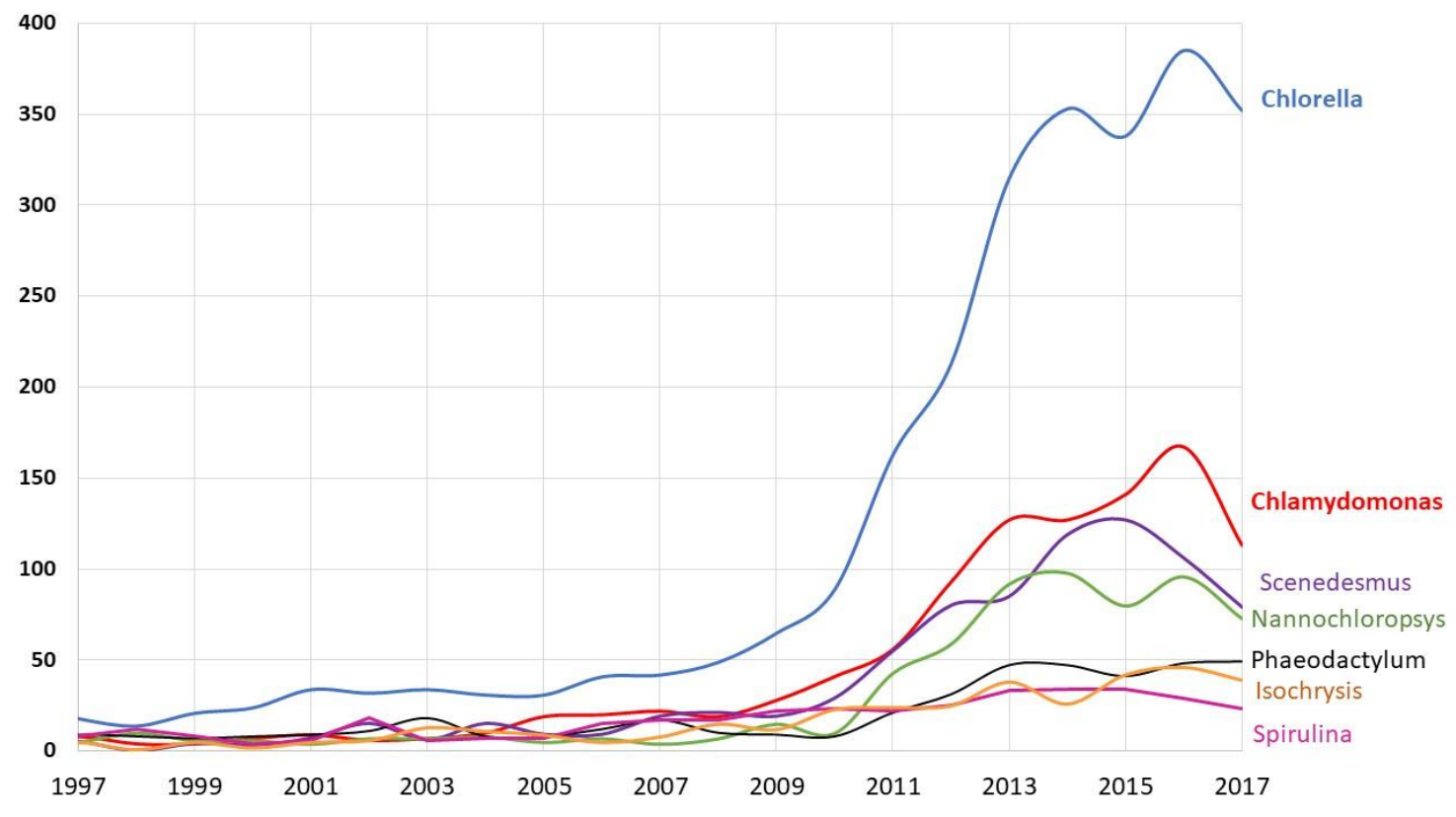

Figure 25.- Time evolution of the publication numbers of the most studied microalgae genres 
